\title{
AN APPROACH TO DETERMINE THE PREVALENCE OF POOR MENTAL HEALTH AMONG URBAN AND RURAL POPULATION IN SERBIA USING PROPENSITY SCORE MATCHING
}

\author{
Milena Šantrić-Milićevićc ${ }^{\text {, Nataša Rosić2 }}{ }^{\text {, Uroš Babić }}{ }^{3}$, Zorica Šupić-Terzić1, Janko Janković1, Jovana Todorović1, \\ Goran Trajković 4 \\ ${ }^{1}$ Institute of Social Medicine, Faculty of Medicine, University of Belgrade, Belgrade, Serbia \\ ${ }^{2}$ Institute of Public Health of the City of Belgrade, Belgrade, Serbia \\ ${ }^{3}$ Clinical Centre of Serbia, Faculty of Medicine, University of Belgrade, Belgrade, Serbia \\ ${ }^{4}$ Institute of Medical Statistics and Informatics, Faculty of Medicine, University of Belgrade, Belgrade, Serbia
}

\section{SUMMARY}

Objective: Studies about mental health among urban and rural residents are scarce. A limited number of studies report somewhat better mental health in rural settings, despite higher rates of suicides. The main objective of this study was to describe social conditions of the population of Serbia in rural and urban settlements and to assess the differences in the prevalence of mental health disorders.

Methods: Propensity score matching of urban and rural persons $(2 \times 3,569$ persons) has eliminated confounding effects from social variables (age, gender, wealth index, education level, employment, family status) and self-rated health. Thus, any statistical differences concerning mental health variables (five-item Mental Health Inventory and clinically diagnosed chronic anxiety or depression) between the two populations were not a result of differences in the matching variables.

Results: After matching all variables, the estimated prevalence rate of poor mental health was significantly higher among residents of urban $(52.2 \%)$ than rural $(49.1 \%)$ settlements $(p=0.012)$.

Conclusions: Almost half of the Serbian population suffers from poor mental health, therefore, there is a need to increase efforts on mental health promotion, prevention and treatment. Our study findings also support the importance of promoting benefits of rural settings for people with mental distress.

Key words: chronic anxiety, depression, mental health inventory, propensity score matching, rural health, social conditions

Address for correspondence: M. Šantrić-Milićević, Institute of Social Medicine, Faculty of Medicine, University of Belgrade, Dr Subotica Street 15, 11000 Belgrade, Serbia. E-mail: msantric@med.bg.ac.rs

https://doi.org/10.21101/cejph.a4160

\section{INTRODUCTION}

Mental health is essential for the functioning and well-being of individuals and communities (1). Adults' mental health is also important for the community since adults take care for children, elderly, frail, and incompetent family members, and are active and productive members of the community (2). Experts estimated that one in four people would be affected by mental and behavioural disorders at some point in their lifetime (3). People with mental health problems are more likely to die prematurely due to risk behaviours, chronic diseases and a lack of quality treatment, and suicide (4). Although depressive disorders are among leading causes of disability worldwide, epidemiological data for major depressive disorders are not available for many low- and middleincome countries (5).

In addition to hereditary and demographic factors, the socioeconomic status is an important factor contributing to inequity in health, including mental health (5). The occurrence and progres- sion of mental health disorders is influenced by the conditions in which people are born, grow, live, work, and age. Therefore, improving social conditions can also reduce mental health inequities. A number of studies describe mental health benefits derived from nature-based therapies (6-9), but there is a lack of evidence about joint impact of the environment and social factors on mental health (10).

Although the studies on mental health of rural population are scarce in Serbia, case reports, small area studies and research focused on particular mental healthcare issues report somewhat better mental health in rural than in urban settings (11). About $85 \%$ of the Serbian territory is rural according to the OECD methodology $(12,13)$. Currently, $40.5 \%$ of the population live in non-urban areas and the number may fall further due to migration flows from rural to urban areas (14).

Rural mental health is underresearched in Serbia. Possible reasons could be theoretical limitations of the concept of rurality, the centralization of mental healthcare system and social care, and 
a lack of official health statistic data, disaggregated by the rural and urban settlements $(15,16)$. However, analyses of population mental health in urban and rural areas are needed to provide information for developing strategies for mental health improvement, and e.g. for the allocation of limited healthcare resources (15).

Natural decline in population, migration and population aging occur in most rural areas in Serbia $(12,14)$. The scarce evidence pointed out that especially women and children in rural areas of Serbia face a number of serious obstacles to accessing important social services (17), as well as information and modern technologies (18). With regard to the evidence of strong relationship between mental health and social circumstances (15), several intense events may have detrimental effect on the mental health of Serbian population. In the 1990s, Serbia was affected by military conflicts, international sanctions, bombing, considerable influxes of refugees and internally displaced persons, economic deprivation, global financial crises, and poverty, which rate has increased significantly in rural population, older people and the poorly educated (19). Nervousness, sadness and fatigue were more common in rural population while stress was present in $43.9 \%$ of residents mainly from urban areas (16). According to the last available estimates of age standardized rates of disability adjusted years of life lost, Serbia was the worst ranked relative to the comparator countries in the year 1990 and in the year 2010, despite small improvement seen during two decades (20). The same estimates showed that Serbia was the best public health performer in 2010 regarding major depressive disorders (20). However, the 2013 National Health Survey did not focus on anxiety disorders or poor mental health as the 2006 National Health Survey. According to the results of the former survey, it focused mainly on residents' perception of depression in terms of self-assessed severity of depression symptoms and regional distribution (not rural urban settlements disaggregation) (21). Consequently, the prevalence rate of poor mental health and anxiety disorders or depression can be drawn only from the 2006 National Health Survey. A national health survey may represent a valuable source of valid information helping to understand social and environmental conditions, their changes and impact on mental health of the population. Accordingly, particularly important are questions about social disparities between rural and urban population, and whether type of residence may be an important factor influencing mental health.

The main objective of this study was to describe social conditions of the population of Serbia in rural and urban settlements and to assess the differences in the prevalence of mental health disorders.

\section{MATERIALS AND METHODS}

\section{Study Design and Sample}

The cross-sectional design was used for this secondary data analysis of the National Health Survey of the Serbian population in 2006 (excluding Kosovo and Metohija) to assess differences in rural and urban population in terms of social determinants, general health and mental health. The National Health Survey was conducted by the Ministry of Health of the Republic of Serbia, with the financial and technical support from the World Bank, World
Health Organization (WHO) and the Institute of Public Health of Serbia (22). This national survey involved 7,673 households (15,563 adults aged 20 years and more), twofold stratified representative sample of households in Serbia. Trained interviewers conducted interviews during September and October 2006. Upon information about the purpose of the study, 14,522 adult respondents (6,858 men and 7,644 women) consented to participate in the study and completed questionnaires (response rate 93.2\%). The questions were part of the validated instrument based on standard questionnaires from similar types of studies $(23,24)$.

\section{Study Variables}

For this study, six social variables, self-rated general health and mental health assessed with two types of measures were selected. Six social variables were the following: age (in six ten-year intervals), gender, place of residence (urban or rural settlement), marital status, education level (categorized according to the International Classification of Education into primary, secondary and tertiary education), employment status (employed, unemployed and inactive), and the Wealth Index (25). The Wealth Index includes variables related to the property excluding income. A specific procedure, described in detail elsewhere, was applied to obtain three categories of the Wealth Index - the rich, the middle class and the poor $(25,26)$.

Respondents rated own general health as good, average or poor. Mental health was assessed with the subjective and the objective measure, both based on respondent reports. The first measure symbolized the perception of psychological disorders measured by the five-item version of Mental Health Inventory (MHI-5), which consists of five questions from the wider version of inventory of 38 questions that best predict the total score $(27,28)$. MHI-5 score measures the overall mental health on a scale from "all the time" (1 point) to "none of the time" ( 6 points), by answering the following five questions: "How long during the past 4 weeks": "Have you felt so depressed that nothing could cheer you up?", "Have you felt calm and peaceful?", "Have you been so nervous?", "Have you felt depressed and sad?", and "Have you been happy?" (27). Complete answers to the aforementioned questions gave 14,186 respondents. Final MHI-5 score was calculated by adding the scores for each question, and converting the scores into a scale from 0 to 100 , where the score of 0 indicated the worst mental health, and the score of 100 represented the optimal mental health. For the purpose of statistical analysis, MHI- 5 score was converted into a binary variable with borderline score 68 (score MHI-5 < 68 indicates poor mental health and score MHI-5 $\geq 68$ good mental health). The second mental health variable was also binary, showing the presence or absence of a clinical diagnosis of chronic anxiety or depression in the last 12 months before the interview $(14,494$ respondents answered completely this question).

\section{Statistical Analyses}

In addition to absolute numbers and relative descriptors, we used Pearson's chi-square test and propensity score matching (PSM). The Pearson's chi-square test tested all statistical differences between the rural and urban populations with regard to social conditions and self-rated health as well as to mental health (done with SPSS v. 22). By using the ability of the PSM, urban 
and rural populations were "balanced" by social conditions and self-rated health, upon which two similar groups consisting of 3,569 persons were extracted from the sample (29). PSM was done by the commonly used method Mahalanobis and propensity score matching with STATA v. 10.0, and commands psmatch2 without replacement and caliper 0.0001 (30). PSM has eliminated confounding effects of age, gender, family status, education level, employment, Wealth Index, and self-rated health in both the urban and the rural groups of residents. After that, the difference of the prevalence of MHI- $5<68$ score (poor mental health) and clinically diagnosed chronic anxiety or depression was examined in matched rural and urban population groups with the Pearson's chi-square test. The rate of missing data for all variables in our data set was below $2.5 \%$. Missing data were not replaced or imputed. We used pairwise deletion to handle missing data. In all analyses, $\mathrm{p}<0.05$ was taken as the minimum level of significance.

\section{RESULTS}

Statistically significant differences were found between the population in rural and urban settlements in terms of social conditions and self-rated general health (Table 1).

In comparison with urban settlements, rural areas were mainly inhabited by persons aged over 60 years $(p<0.001)$, male residents $(p=0.001)$, persons living in marriage or with partner $(p<0.001)$, and poorly educated $(\mathrm{p}<0.001)$. More inactive and unemployed persons were found in rural than in urban settlements $(p<0.001)$. Rural and urban settlements differed significantly by the Wealth Index ( $<<0.001)$; for example, more than $65 \%$ of the rural population was poor whilst more than $56 \%$ of urban population was rich. It was further noted that significantly more rural than urban residents rated own general health as bad (19.9\% vs. $14.5 \%)$, while good health was rated by $42.6 \%$ of rural residents vs. $46.8 \%$ of urban residents $(\mathrm{p}<0.001)$.

Table 1. Social conditions and self-rated health of respondents before matching, grouped by type of settlement

\begin{tabular}{|c|c|c|c|c|}
\hline \multirow{2}{*}{ Variables } & \multirow{2}{*}{$\begin{array}{l}\text { Total } \\
\text { n (\%) }\end{array}$} & \multicolumn{3}{|c|}{ Type of settlement, $n(\%)$} \\
\hline & & Urban & Rural & $p$ \\
\hline Age years, total & $14,522(100)$ & $7,528(100)$ & $6,994(100)$ & \multirow{7}{*}{$<0.001$} \\
\hline $20-29$ & $2,180(15)$ & $1,194(15.9)$ & $986(14.1)$ & \\
\hline $30-39$ & $2,307(15.9)$ & $1,240(16.5)$ & $1,067(15.3)$ & \\
\hline $40-49$ & $2,513(17.3)$ & $1,356(18.0)$ & $1,157(16.5)$ & \\
\hline $50-59$ & $2,877(19.8)$ & $1,543(20.5)$ & $1,334(19.1)$ & \\
\hline $60-69$ & $2,210(15.2)$ & $1,114(14.8)$ & $1,096(15.7)$ & \\
\hline $70+$ & $2,435(16.8)$ & $1,081(14.4)$ & $1,354(19.4)$ & \\
\hline Gender, total & $14,522(100)$ & $7,528(100)$ & $6,994(100)$ & \multirow{3}{*}{0.001} \\
\hline Female & $7,664(52.8)$ & $4,074(54.1)$ & $3,590(51.3)$ & \\
\hline Male & $6,858(47.2)$ & $3,454(45.9)$ & $3,404(48.7)$ & \\
\hline Marital status, total & $14,467(100)$ & $7,498(100)$ & $6,969(100)$ & \multirow{3}{*}{$<0.001$} \\
\hline Married/with partner & $9,914(68.5)$ & $4,962(66.2)$ & $4,952(71.1)$ & \\
\hline Single/divorced/widowed & $4,553(31.5)$ & $2,536(33.8)$ & $2,017(28.9)$ & \\
\hline Education level, total & $14,522(100)$ & $7,528(100)$ & $6,994(100)$ & \multirow{4}{*}{$<0.001$} \\
\hline High & $1,835(12.6)$ & $1,443(19.2)$ & $392(5.6)$ & \\
\hline Middle & $6,935(47.8)$ & $4,114(54.6)$ & $2,821(40.3)$ & \\
\hline Low & $5,752(39.6)$ & $1,971(26.2)$ & $3,781(54.1)$ & \\
\hline Employment status, total & $14,505(100)$ & $7,523(100)$ & $6,982(100)$ & \multirow{4}{*}{$<0.001$} \\
\hline Employed & $5,250(36.2)$ & $3,042(40.4)$ & $2,208(31.6)$ & \\
\hline Unemployed & $2,670(18.4)$ & $1,285(17.1)$ & $1,385(19.8)$ & \\
\hline Inactive & $6,585(45.4)$ & $3,196(42.5)$ & $3,389(48.5)$ & \\
\hline Wealth index, total & $14,522(100)$ & $7,528(100)$ & $6,994(100)$ & \multirow{4}{*}{$<0.001$} \\
\hline Rich & $5,165(35.6)$ & $4,284(56.9)$ & $881(12.6)$ & \\
\hline Middle class & $3,010(20.7)$ & $1,468(19.5)$ & $1,542(22.0)$ & \\
\hline Poor & $6,347(43.7)$ & $1,776(23.6)$ & $4,571(65.4)$ & \\
\hline Self-rated health, total & $14,488(100)$ & $7,508(100)$ & $6,980(100)$ & \multirow{4}{*}{$<0.001$} \\
\hline $\mathrm{Bad}$ & $2,477(17.1)$ & $1,090(14.5)$ & $1,387(19.9)$ & \\
\hline Average & $5,519(38.1)$ & 2,901 (38.6) & $2,618(37.5)$ & \\
\hline Good & $6,492(44.8)$ & $3,517(46.8)$ & $2,975(42.6)$ & \\
\hline
\end{tabular}


After matching rural and urban population with the propensity score, population groups from both settlements that had no statistically significant differences were extracted with regard to age and gender structure, marriage and employment status, education and Wealth Index, and general health self-ratings (Table 2).

Table 3 presents that before matching, the prevalence rates of both poor mental health and chronic anxiety or depression were significantly higher $(\mathrm{p}<0.001)$ in rural settlements $(50.3 \%$ and $5.3 \%$ ) than in urban population $(46.7 \%$ and $4.5 \%)$. The matched urban and rural populations were significantly different only in regard to the prevalence of poor mental health measured with MIH-5 score. Precisely, $47.8 \%$ of rural residents vs. $50.9 \%$ of urban residents estimated their mental health as poor $(p=0.012)$. Percentage of persons with clinical diagnosis of chronic anxiety or depression in rural and urban settlements was similar, $4.9 \%$ vs. $5 \%(\mathrm{p}=0.822)$.

\section{DISCUSSION}

After matching for social variables and self-rated health, the prevalence of poor mental health was high, it was present in almost $50 \%$ of the population, but it was lower in rural than in urban residents of Serbia. This finding is in agreement with studies which also found that people in rural settlements have better mental health (31-33), but the results from the literature are rather inconsistent $(34,35)$. For example, ESEMeD study (35) examined differences in mental health between rural and urban population in six European countries. Although the study found that in overall sample there was a higher prevalence of mental disorders in urban population, the opposite was true for France and Germany.

Several factors can explain the small but significant difference in the prevalence rate of poor mental health. For instance, recent

Table 2. Social conditions and self-rated health of respondents after matching, grouped by type of settlement

\begin{tabular}{|c|c|c|c|c|}
\hline \multirow{2}{*}{ Variables } & \multirow{2}{*}{ Total, $\mathrm{n}(\%)$} & \multicolumn{3}{|c|}{ Type of settlement, $n(\%)$} \\
\hline & & Urban & Rural & $\mathrm{p}$ \\
\hline Age years, total & $7,138(100)$ & $3,569(100)$ & $3,569(100)$ & \multirow{7}{*}{0.792} \\
\hline $20-29$ & $1,086(15.2)$ & $540(15.1)$ & $546(15.3)$ & \\
\hline $30-39$ & $1,160(16.3)$ & $577(16.2)$ & $583(16.3)$ & \\
\hline $40-49$ & $1,268(17.8)$ & $626(17.5)$ & $642(18.0)$ & \\
\hline $50-59$ & $1,421(19.9)$ & $731(20.5)$ & $690(19.3)$ & \\
\hline $60-69$ & $1,042(14.6)$ & $507(14.2)$ & $535(15.0)$ & \\
\hline $70+$ & $1,161(16.3)$ & $588(16.5)$ & $573(16.1)$ & \\
\hline Gender, total & $7,138(100)$ & $3,569(100)$ & $3,569(100)$ & \multirow{3}{*}{0.652} \\
\hline Female & $3,744(52.5)$ & $1,862(52.2)$ & $1,882(52.7)$ & \\
\hline Male & $3,394(47.5)$ & $1,707(47.8)$ & $1,687(47.3)$ & \\
\hline Marital status, total & $7,138(100)$ & $3,569(100)$ & $3,569(100)$ & \multirow{3}{*}{1.000} \\
\hline Married/with partner & $5,008(70.2)$ & $2,504(70.2)$ & $2,504(70.2)$ & \\
\hline Single/divorced/widowed & $2,130(29.8)$ & $1,065(29.8)$ & $1,065(29.8)$ & \\
\hline Education level, total & $7,138(100)$ & $3,569(100)$ & $3,569(100)$ & \multirow{4}{*}{0.636} \\
\hline High & $501(7.0)$ & $241(6.8)$ & $260(7.3)$ & \\
\hline Middle & $3,629(50.8)$ & $1,827(51.2)$ & $1,802(50.5)$ & \\
\hline Low & $3,008(42.1)$ & $1,501(42.1)$ & $1,507(42.2)$ & \\
\hline Employment status, total & $7,138(100)$ & $3,569(100)$ & $3,569(100)$ & \multirow{4}{*}{0.084} \\
\hline Employed & $2,520(35.3)$ & $1,242(34.8)$ & $1,278(35.8)$ & \\
\hline Unemployed & $1,419(19.9)$ & $747(20.9)$ & $672(18.8)$ & \\
\hline Inactive & $3,199(44.8)$ & $1,580(44.3)$ & $1,619(45.4)$ & \\
\hline Wealth index, total & $7,138(100)$ & $3,569(100)$ & $3,569(100)$ & \multirow{4}{*}{0.997} \\
\hline Rich & $1,666(23.3)$ & $833(23.3)$ & $833(23.3)$ & \\
\hline Middle class & $2,169(30.4)$ & $1,086(30.4)$ & $1,083(30.3)$ & \\
\hline Poor & $3,303(46.3)$ & $1,650(46.2)$ & $1,653(46.3)$ & \\
\hline Self-rated health, total & $7,138(100)$ & $3,569(100)$ & $3,569(100)$ & \multirow{4}{*}{0.584} \\
\hline Bad & $1,211(17.0)$ & $621(17.4)$ & $590(16.5)$ & \\
\hline Average & $2,715(38.0)$ & $1,357(38.0)$ & $1,358(38.0)$ & \\
\hline Good & $3,212(45.0)$ & $1,591(44.6)$ & $1,621(45.4)$ & \\
\hline
\end{tabular}


Table 3. Differences in the prevalence of poor mental health and chronic anxiety/depression among residents from urban and rural settlements, before and after matching with propensity score matching

\begin{tabular}{|c|c|c|c|c|c|c|c|}
\hline & \multirow{2}{*}{$\begin{array}{l}\text { Residents' type } \\
\text { of settlement }\end{array}$} & \multicolumn{3}{|c|}{ Five-item Mental Health Inventory (MHI-5) score } & \multicolumn{3}{|c|}{ Clinically diagnosed chronic anxiety/depression } \\
\hline & & Total & $\geq 68$ & $<68$ & Total & Yes & No \\
\hline \multirow{4}{*}{ Before matching } & Total, $n(\%)$ & $14,186(100)$ & $7,319(51.6)$ & $6,867(48.4)$ & $14,494(100)$ & $713(4.9)$ & $13,781(95.1)$ \\
\hline & Urban, $\mathrm{n}(\%)$ & $7,371(100)$ & $3,931(53.3)$ & $3,440(46.7)$ & $7,518(100)$ & $340(4.5)$ & $7,178(95.5)$ \\
\hline & Rural, $n(\%)$ & $6,815(100)$ & $3,388(49.7)$ & $3,427(50.3)$ & $6,976(100)$ & $373(5.3)$ & $6,603(94.7)$ \\
\hline & $p^{*}$ & \multicolumn{3}{|c|}{$<0.001$} & \multicolumn{3}{|c|}{$<0.001$} \\
\hline \multirow{4}{*}{ After matching } & Total, $\mathrm{n}(\%)$ & $6,972(100)$ & $3,530(50.6)$ & $3,442(49.4)$ & $7,126(100)$ & $350(4.9)$ & $6,776(95.1)$ \\
\hline & Urban, n (\%) & $3,513(100)$ & $1,726(49.1)$ & $1,787(50.9)$ & $3,564(100)$ & $173(4.9)$ & $3,391(95.1)$ \\
\hline & Rural, n (\%) & $3,459(100)$ & $1,804(52.2)$ & $1,655(47.8)$ & $3,562(100)$ & $177(5.0)$ & $3,385(95.0)$ \\
\hline & $p^{*}$ & \multicolumn{3}{|c|}{0.012} & \multicolumn{3}{|c|}{0.822} \\
\hline
\end{tabular}

${ }^{*} \mathrm{p}$ - Pearson's chi-square, MHI-5 score $\geq 68$ : good mental health; MHI-5 score <68: poor mental health

research has pointed out that job loss, low-income, and failures to meet the everyday needs related to macroeconomic shocks have considerable negative effects on population's health $(36,37)$. For decades, urban settlements have recorded influxes of more educated working-age populations searching for better-paid job and economic security $(12,14,19)$, while it was shown that larger number of people with work experience of more than 30 years live in rural (24\%) than in urban (12\%) areas (16). Therefore, urban areas had more persons potentially exposed to macroeconomic failures and related negative effects on mental health. Highest percentage of persons living in Serbian rural areas was older than 70 years and economically inactive (16).

Moreover, urban populations are nowadays exposed to increasing industrial pollution, in addition to other health determinants (38). However, rural population may be more vulnerable to economic downturns because of their economic specialization and dependence on the climate factors (e.g. drought and floods) (15).

Lower prevalence rate of poor mental health in rural areas than in urban areas can be attributed to a beneficial way of life in rural settlements. Residing in rural environment represents longer stay in the open air and greater physical activity than in urban areas (6). Positive effects of time spent in natural environment could be confirmed by the study from Japan that showed that even allotment gardening improves mental health (39). These results were also confirmed by meta-analysis (40). Even so, more research is needed to outline the effects of environmental and behaviour risk factors and social capital on mental health of the population in urban and rural settlements.

In our study, after eliminating confounding effects of social conditions and self-rated health, there was no statistically significant difference found in the prevalence of clinically diagnosed chronic anxiety or depression between urban and rural residents. Other researchers have noted higher incidence of depression and suicide in rural than in urban settlements (41). With regard to estimates for Europe, $5 \%$ of the population with chronic anxiety or depression falls somewhere in between the prevalence of $0.8 \%$ for chronic anxiety (42) and the prevalence of $13.6 \%$ for any anxiety disorder (43), and 8.6\% for overall depressive disorders (44).

Since PSM eliminated possible confounding effects of described social variables and self-rated health, results based on the matched samples equal to about $49 \%$ of the representative population sample. Nevertheless, study findings might have been over- or under-estimated due to respondents' memory or readiness to outline personal emotions or data. Rural and urban populations have distinct socio-cultural milieu, which could have shaped the respondent answers (43). Rural residents are used to hard work without complaining and leisure. They are also more likely to hide mental disorders in order to preserve privacy and independence and avoid stigmatization. In line with that, people from rural areas are significantly less likely to seek professional help for mental health disorders than people from urban areas (45). Furthermore, their level of information about mental health disorders could be also a barrier to seek professional help on time. Increased prevention and treatment are needed for almost half of the Serbian population suffering from poor mental health. More research about the knowledge and attitudes toward mental healthcare seeking behaviour and about healthcare utilization and mental healthcare delivery in both types of settlements in Serbia can provide more information to better understand the differences in mental health. The study findings cannot be generalized to persons under the age of 20 years.

This study is the first one that outlined the prevalence of subjectively assessed poor mental health and clinically diagnosed chronic anxiety or depression in the Serbian population. Serbia is a country where rural areas with low population density cover large parts of the territory (12). It can help in developing programmes for mental recovery or regeneration in rural settlements. Since Serbian population is aging and the number of elderly people will increase in the coming years, not all social inequities and mental health inequality could be alleviated or prevented. Thus, it points to the importance of investing in programmes for the promotion of mental health and prevention of mental disorders. In conclusion, almost half of the Serbian population suffers from poor mental health. Mental health was better in rural than in urban areas. Based on the current research, mental health remediation should be priority in the environment and health domain of local communities as well. Moreover, the future research on national level should include comprehensive mental health and its further monitoring and assessment.

\section{Acknowledgements}

The study was supported by the Ministry of Education, Science and Technology of the Republic of Serbia (Grant No. 175087, Grant No. 41004, Grant No. 175042). 


\section{Conflict of Interests}

None declared

\section{Ethical Approval}

The Ministry of Health of the Republic of Serbia and the Ethics Committee of the Institute of Public Health of Serbia have approved the study.

\section{REFERENCES}

1. World Health Organization, Department of Mental Health and Substance Abuse; Victorian Health Promotion Foundation, University of Melbourne. Promoting mental health: concepts, emerging evidence, practice. Summary report. Geneva: WHO; 2005.

2. Min JA, Lee CU, Lee C. Mental health promotion and illness prevention: a challenge for psychiatrists. Psychiatry Investig. 2013 Dec;10(4):307-16

3. World Health Organization, Department of Mental Health and Substance; Prevention Research Centre of the Universities of Nijmegen and Maastricht. Prevention of mental disorders: effective interventions and policy options: summary report. Geneva: WHO; 2004.

4. WHO Regional Office for Europe. The European mental health action plan. Regional Committee for Europe. Sixty-third session EUR/RC63/11 + EUR/RC63/CONF.DOC./8. Copenhagen: WHO Regional Office for Europe; 2013.

5. Patel V, Lund C, Hatherill S, Plagerson S, Corrigall J, Funk M, et al. Mental disorders: equity and social determinants. In: Blas A, Kurup AS editors. Equity, social determinants and public health programs. Geneva: WHO; 2010. p. 115-34

6. Townsend M, Weerasuriya R. Beyond blue to green: the benefits of contact with nature for mental health and well-being. Melbourne, Australia: Beyond Blue Limited; 2010.

7. Corazon SS, Stigsdotter UK, Jensen AGC, Nilsson K. Development of the nature-based therapy concept for patients with stress-related illness at the Danish healing forest garden Nacadia. J Ther Horticult. 2010;20:30-48.

8. Bowler DE, Buyung-Ali LM, Knight TM, Pullin AS. A systematic review of evidence for the added benefits to health of exposure to natural environments. BMC Public Health. 2010 Aug 4;10:456. doi: 10.1186/14712458-10-456.

9. Keniger LE, Gaston KJ, Irvine KN, Fuller RA. What are the benefits of interacting with nature? Int J Environ Res Public Health. 2013 Mar 6;10(3):913-35.

10. Braubach M, Martuzzi M, Racioppi F, Krzyzanowski M. On the way to Parma: understanding and addressing the influence that social inequities have on environmental health. Eur J Public Health. 2010 Feb;20(1):12-3.

11. Lecic-Tosevski D. Mental health of the rural population: a neglected area in psychiatry. In: Proceedings of the conference. The health of the rural population; 2014 Oct 21-22; Belgrade. Belgrade: Serbian Academy of Sciences and Arts; 2014. p. 20. (In Serbian.)

12. Gligorijević V, Devedžić M. Changes in the distribution of rural population in Serbia. Collection of papers - Faculty of Geography at the University of Belgrade. 2011;59:1-24. (In Serbian, English.)

13. Directorate for Public Governance and Territorial Development. OECD regional typology. Paris: OECD; 2011.

14. Statistical Office of the Republic of Serbia. 2011 Census of population, households and dwellings in the Republic of Serbia. Population by age, sex and settlements. Belgrade: Statistical Office of the Republic of Serbia; 2011.

15. Hart LG, Larson EH, Lishner DM. Rural definitions for health policy and research. Am J Public Health. 2005 Jul;95(7):1149-55.

16. Government of the Republic of Serbia. National strategy for the development of mental health protection. Službeni glasnik Republike Srbije [Internet]. 2007 [cited 2017 Jan 27];(8). Available from: http://www. pravno-informacioni-sistem.rs/SlGlasnikPortal/arhslgl/SGARHSTARO/ numberOverview?numberId=20307. (In Serbian.)

17. Bogdanov N, Tomanović S, Cvejić S, Babovic M, Vukovic O. Access to services of rural areas for women and children of Serbia and measures for improve their situation. Belgrade: UNICEF Serbia; 2011

18. Statistical Office of the Republic of Serbia. Serbia multiple indicator cluster survey 2010, Belgrade: Statistical Office of the Republic of Serbia, Republic of Serbia; 2011.

19. Ministry of Economy and Regional Development of the Republic of Serbia. The National employment strategy for the period 2011-2020. Službeni glasnik Republike Srbije [Internet]. 2011 [cited 2017 Jan 27];(37). Avail- able from: http://www.pravno-informacioni-sistem.rs/SlGlasnikPortal/ arhslgl/SGARHSTARO/numberOverview?numberId=9975. (In Serbian.)

20. GBD profile: Serbia. Global Burden of Diseases, Injuries, and Risk Factors Study 2010 [Internet]. Seattle: Institute for Health Metrics and Evaluation [cited 2014 Sep 1]. Available from: http://www.healthdata. $\mathrm{org} / \mathrm{sites} / \mathrm{default} / \mathrm{files} /$ files/country_profiles/GBD/ihme_gbd_country_report serbia.pdf.

21. Institute of Public Health of Serbia. Results of the national health survey of the Republic of Serbia 2013 [Internet]. Belgrade, Serbia: Institute of Public Health of Serbia; 2014 [cited 2017 Jan 27]. Available from: http:// www.batut.org.rs/download/publikacije/2013SerbiaHealthSurvey.pdf.

22. Institute of Public Health of Serbia. Results of the national health survey of the Republic of Serbia 2006 [Internet]. Belgrade, Serbia, Institute of Public Health of Serbia; 2007 [cited 2017 Jan 27]. Available from: http://www.batut.org.rs/download/publikacije/National\%20Health\%20 Survey\%20Serbia\%202006.pdf.

23. World Health Organization. Health statistics and health information systems. World Health Survey [Internet]. Geneva: WHO [cited 2014 Nov 1]. Available from: http://www.who.int/healthinfo/survey/en.

24. SF-36.org. A community for measuring health outcomes using SF tools [Internet]. [cited 2014 Nov 1]. Available from: http://www.sf-36.org.

25. Rutstein SO, Johnson K. The DHS Wealth Index. DHS Comparative Reports No. 6. Calverton, Maryland: ORC Macro; 2004.

26. Jankovic J, Marinkovic J, Simic S. Utility of data from a national health survey: do socioeconomic inequalities in morbidity exist in Serbia? Scand J Public Health. 2011 May;39(3):230-8.

27. Mental Health National Outcomes and Casemix Collection: Overview of clinician-rated and consumer self-report measures, Version 1.50. Canberra: Department of Health and Ageing; 2003.

28. Thorsen SV, Rugulies R, Hjarsbech PU, Bjorner JB. The predictive value of mental health for long-term sickness absence: the Major Depression Inventory (MDI) and the Mental Health Inventory (MHI-5) compared. BMC Med Res Methodol. 2013 Sep 17;13:115. doi: 10.1186/1471-228813-115.

29. Austin PC. An introduction to propensity score methods for reducing the effects of confounding in observational studies. Multivariate Behav Res. 2011 May;46(3):399-424.

30. Leuven E, Sianesi B. PSMATCH2: Stata module to perform full Mahalanobis and propensity score matching, common support graphing, and covariate imbalance testing. Chestnut Hill: Boston College Department of Economics in its series Statistical Software Components S432001; 2003.

31. Riva M, Bambra C, Curtis S, Gauvin L. Collective resources or local social inequalities? Examining the social determinants of mental health in rural areas. Eur J Public Health. 2011 Apr;21(2):197-203.

32. Zagozdzon P, Kolarzyk E, Marcinkowski JT. Quality of life and rural place of residence in Polish women - population based study. Ann Agric Environ Med. 2011;18(2):429-32.

33. Hillemeier MM, Weisman CS, Chase GA, Dyer AM. Mental health status among rural women of reproductive age: findings from the Central Pennsylvania Women's Health Study. Am J Public Health. 2008 Jul;98(7):1271-9.

34. Probst JC, Laditka SB, Moore CG, Harun N, Powell MP, Baxley EG. Rural-urban differences in depression prevalence: implications for family medicine. Fam Med. 2006 Oct;38(9):653-60.

35. Kovess-Masféty V, Alonso J, de Graaf R, Demyttenaere K. A European approach to rural-urban differences in mental health: the ESEMeD 2000 comparative study. Can J Psychiatry. 2005 Dec;50(14):926-36.

36. Kondo N. Socioeconomic disparities and health: impacts and pathways. J Epidemiol. 2012;22(1):2-6.

37. Giatti L, Barreto SM, César CC. Unemployment and self-rated health: neighborhood influence. Soc Sci Med. 2010 Aug;71(4):815-23.

38. Martuzzi M, Pasetto R, Martin-Olmedo P. Industrially contaminated sites and health. J Environ Public Health. 2014;2014:198574. doi: 10.1155/2014/198574.

39. Soga M, Cox D, Yamaura Y, Gaston K, Kurisu K, Hanaki K. Health benefits of urban allotment gardening: improved physical and psychological well-being and social integration. Int J Environ Res Public Health [Internet]. 2017 [cited 2017 Jan 21];14(1):71. Available from: http://www. mdpi.com/1660-4601/14/1/71.

40. Soga M, Gaston KJ, Yamaura Y. Gardening is beneficial for health: A meta-analysis. Prev Med Rep. 2016 Nov 14;5:92-9.

41. Zhang J, Xiao S, Zhou L. Mental disorders and suicide among young rural Chinese: a case-control psychological autopsy study. Am J Psychiatry. $2010 \mathrm{Jul} ; 167(7): 773-81$ 
42. Hofmann SG, Anu Asnaani MA, Hinton DE. Cultural aspects in social anxiety and social anxiety disorder. Depress Anxiety. 2010 Dec;27(12):1117-27.

43. Ayuso-Mateos JL, Vázquez-Barquero JL, Dowrick C, Lehtinen V, Dalgard OS, et al.; ODIN Group. Depressive disorders in Europe: prevalence figures from the ODIN study. Br J Psychiatry. 2001 Oct;179:308-16.

44. Alonso J, Angermeyer MC, Bernert S, Bruffaerts R, Brugha TS, Bryson $\mathrm{H}$, et al.; ESEMeD/MHEDEA 2000 Investigators, European Study of the Epidemiology of Mental Disorders (ESEMeD) Project. Prevalence of mental disorders in Europe: results from the European Study of the
Epidemiology of Mental Disorders (ESEMeD) project. Acta Psychiatr Scand Suppl. 2004;(420):21-7.

45. Caldwell TM, Jorm AF, Dear KB. Suicide and mental health in rural, remote and metropolitan areas in Australia. Med J Aust. 2004 Oct 4;181(7 Suppl):S10-4

Received November 4, 2014 Accepted in revised form January 27, 2017 